\title{
Ultrasound-Guided Transverse Thoracic Muscle \\ Plane Injection vs. Topical Spraying of Papaverine for LIMA Harvesting: A Pilot Study
}

Etik Kurul Onayı: Atatürk Üniversitesi Tıp Fakültesi Klinik Araştırmalar Etik Kurulu’ndan onay alınmış̧ır (26.09.2019 / B.30.2.ATA.0.01.00/572 26.12.2019/8-3).

Çıkar Çatışması: Çalısmaya ait herhangi bir çıkar çatıssması bulunmamaktadır.

Finansal Destek: Çalısma ile ilgili herhangi bir finansal destek bulunmamaktadı. Hasta Onamı: Tüm hastalardan çalıșma için yazılı onam alındı.
Ethics Committee Approval: Approval was obtained from Atatürk University Faculty of Medicine Clinical Research Ethics Committee (26.09.2019 / B.30.2.ATA.0.01.00 / 572 26.12.2019 / 8-3). Conflict of Interest: There is no conflict of interest regarding the study.

Funding: There is no funding for this study.

Informed Consent: Written consent was obtained from all patients for the study.

Cite as: Aydın ME, Al S, Yayık AM, Kaya U, Çolak A. LIMA serbestleştirilmesi için papaverinin ultrason kılavuzluğunda transvers torasik kas düzlemine enjeksiyonu ile topikal uygulamasının karşılaștırılması: Bir pilot çalışma. GKDA Derg. 2021;27(1):14-20.

Öz

Amaç: Topikal papaverin uygulamasının sol internal meme arteri (LIMA) akımı üzerine etkisi iyi bilinen bir uygulama olmasına rağmen, transvers torasik kas planına uygulanan papaverin hidrodiseksiyonunun etkisi bilinmemektedir. Bu çalışmanın amacı, preoperatif ultrason eşliğinde transvers torasik kas planına uygulanan papaverinin LIMA akımı üzerine olan etkisini araștırmaktır.

Yöntem: ASA II-III, koroner arter baypas greftleme cerrahisi geçiren, 40 hasta, randomize olarak iki gruba ayrıldı. Grup topikal papaverin (Grup TP, $n=20$ ) Grup ultrason eşliğinde papaverin (Grup USP n=20). Grup TP'ye $10 \mathrm{mg}$ papaverin $10 \mathrm{~mL}$ salin içerisinde LIMA serbestlestirildikten sonra topika olarak uygulandı. Grup USP'ye ise aynı solüsyon ultrason eşliğinde Preoperatif transvers torasik kas planına uygulandı. Trans-time akım ölçümleri (TTFM) ve LIMA serbestleştirme zamanı, cerrah memnuniyeti kaydedildi.

Bulgular: Anastomoz öncesinde LIMA serbest akımları Grup USP ve Grup TP arasında fark yoktu (111.35 \pm 69.76 vs. $92.15 \pm 46.76$ sırasıyla, $p=0.185)$. Anastomoz sonrasında değerlendirilen TTFM değerleri arasında gruplar arasında anlamlı bir fark yoktu ( $p>0.05)$. LIMA serbestleștirilme süresi

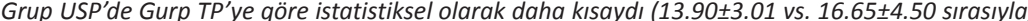
$p=0.049)$. Grup USP'de cerrah LIMA serbestleştirme memnuniyeti istatistiksel olarak anlamlı düzeyde yüksekti $(p=0.029)$.

Sonuç: Ultrason esliğinde transvers torasik kas planına uygulanan papaverin enjeksiyonunun LIMA spazmını önlemek için topikal uygulamaya alternatif bir yöntem olabileceğini düşünmekteyiz.

Anahtar kelimeler: ultrason, transvers torasik kas, papaverin, trans-time akım

\section{ABSTRACT}

Objective: Although the effect of topical papaverine on the left internal mammary artery (LIMA) flow is a well-known method, papaverine hydro dissection is applied to the transverse thoracic muscle plane is unknown. This study aims to investigate the effect of ultrasound-guided transverse thoracic muscle plane papaverine injection on LIMA flow.

Method: ASA II-III, 40 patients who underwent coronary artery bypass grafting surgery, were randomly divided into two groups. Group topical papaverine (Group TP, $n=20$ ) and Group ultrasound-guided papaverine (Group USP, n=20). In Group TP, $10 \mathrm{mg}$ papaverine in $10 \mathrm{~mL}$ saline was administered topically after LIMA harvesting. In Group USP, ultrasound-guided transverse thoracic muscle plane papaverine injection with the same solution preoperatively. Trans-time flow measurements (TTFM), LIMA harvesting time, and surgeon satisfaction were recorded.

Results: There was no difference in LIMA free flows before anastomosis between Group USP and Group TP (111.35 \pm 69.76 vs. 92.15 \pm 46.76 , respectively, $p=0.185)$. There was no significant difference between the groups in TTFM values evaluated after anastomosis ( $p>0.05)$. LIMA harvesting time was statistically shorter in Group USP than Group TP (13.90 \pm 3.01 vs. $16.65 \pm 4.50$ respectively, $p=0.049)$. Surgeon LIMA harvest satisfaction was statistically significantly higher in group USP ( $p=0.029)$.

Conclusion: We think that papaverine injection via ultrasound-guided transverse thoracic muscle plane may be an alternative method to topical application to prevent LIMA spasm.
Received/Geliş: 28.11.2020

Accepted/Kabul: 16.02.2021

Published Online/Online yayın: 23.03.2021

Muhammed Enes Aydın Atatürk Üniversitesi Tıp Fakültesi Anesteziyoloji ve Reanimasyon Anabilim Dalı Erzurum - Türkiye

- enesmd@msn.com ORCID: 0000-0001-8491-6566

S. Al 0000-0001-9283-6814 Atatürk Üniversitesi Tıp Fakültesi Anesteziyoloji ve Reanimasyon Anabilim Dalı Erzurum, Türkiye

A. M. Yayık 0000-0002-2783-7041 Atatürk Üniversitesi Tıp Fakültesi Klinik Araştırma, Geliştirme ve Tasarım Uygulama ve Araștirma Merkezi, Erzurum, Türkiye

U. Kaya 0000-0003-2000-6090 A. Çolak 0000-0002-1380-9779 Atatürk Üniversitesi Tıp Fakültesi Kalp-Damar Cerrahisi Anabilim Dalı Erzurum, Türkiye

Keywords: ultrasound, transverse thoracic muscle, papaverine, trans-time flow

(C) Telif hakkı Göğüs Kalp Damar Anestezi ve Yoğun Bakım Derneği'ne aittir. Logos Tıp Yayıncılık tarafindan yayınlanmaktadır. Bu dergide yayınlanan bütün makaleler Creative Commons Attf-Gayri Ticari 4.0 Uluslararası Lisansı ile lisanslanmıştır.

(c) Copyright The Society of Thoracic Cardio-Vascular Anaesthesia and Intensive Care. This journal published by Logos Medical Publishing. Licenced by Creative Commons Attribution-NonCommercial 4.0 International (CC BY) 
M. E. Aydın ve ark., LIMA Serbestleştirilmesi için Papaverinin Transvers Torasik Kas Düzlemi Enjeksiyonu ile Topikal Uygulamasının Karşılaştırılması

\section{Giriş}

Kalp baypas cerrahisi olarak da bilinen koroner arter baypas greftleme (CABG), koroner arterlerdeki darlık nedeniyle azalmış kan akışını iyileştirmek için gerçekleştirilen bir prosedürdür. Koroner arterlerden sol ön inen (LAD) koroner arterin greflenmesi için genellikle sol internal meme arteri (LIMA) tercih edilen perforatör arterdir. Ancak, anastomoz yapılmak üzere serbestleştirilmesi aşamasında oluşan spazm sıklıkla cerrahi diseksiyonu ve anastomozu güçleştirmekte ve akım dinamiklerini olumsuz etkilemektedir ${ }^{[1,2]}$.

Bu spazmın tedavisinde kalsiyum kanal blokerleri, sodyum nitroprusid, nitrogliserin, milrinon ve fenoksibenzamin gibi birçok farmakolojik ajan kullanılmış olsa da papaverin günümüzde birçok merkezde rutin olarak tercih edilmektedir ${ }^{[3-5]}$. Intralüminal, perivasküler ve topikal uygulamalar geleneksel olarak yaygın kullanılan yöntemlerdir ${ }^{[5]}$.

Ultrasonun özellikle analjezi amacıyla anestezi pratiğinde kullanımı giderek yayınlaşmaktadır. Özellikle her gün bir yenisi tanımlanan plan blokları ile anestezistlerin bölgesel yapılara sonoanatomik egemenliği artmaktadır. Poststernotomi ağrısı için analjezi amacıyla uyguladığımız transversus torasik kas plan bloğu deneyimlerimiz sırasında bu kas planına enjekte edilen lokal anesteziğin LIMA etrafında hidrodiseksiyon oluşturarak bir depozit meydana getirdiğini fark ettik ${ }^{[6]}$. Bu deneyim ile transversus torasik kas planına lokal anestezik yerine papaverin enjekte ederek LIMA serbestleştirilmesi işlemi öncesinde bir spazm önleyici etki sağlayabileceğimiz hipotezi üzerine çalışmamızı tasarladık.

Bu çalışmanın primer amacı, LIMA serbestleştirilmeden ve bölgesel anatomik yapıların bütünlüğü bozulmadan ultrason eşliğinde papaverin uygulanması yöntemi ile geleneksel bir yöntem olan topikal papaverin uygulamasının anastomoz öncesi ve sonrasında ölçülen LIMA akımını üzerine etkisini araştırmaktır. LIMA serbestleştirilmesi aşamasında cerrahi diseksiyon üzerine etkileri ise çalışmanın sekonder amaçlarıdır.

\section{GEREÇ ve YÖNTEM}

Çalışma, Atatürk Üniversitesi Tıp Fakültesi Klinik Araştırma Etik Komitesi'nin yerel kurumsal inceleme kurulu (Atatürk Üniversitesi Etik Kurulu- No: B.30.2.ATA.0.01.00/572 26.12.2019/8-3) tarafından 26 Eylül 2019 tarihinde onaylandı ve tüm hastalardan çalışma için yazıı onam alındı.

Çalışmaya 1 Ocak 2020-1 Haziran 2020 tarihleri arasında kliniğimizde LAD grefti için perforator olarak LIMA'nın tercih edildiği koroner arter baypas greftleme cerrahisi uygulanan, ASA II-III, 40 hasta dâhil edildi. Acil cerrahiler, eşlik eden kapak cerrahileri, son dönem organ yetersizlikleri, preoperatif dönemde atriyal fibrilasyon gibi aritmisi olan hastalar, preoperatif ejeksiyon fraksiyonu (EF) \%40'tan daha düşük olan hastalar ve çalışmaya katılmayı reddeden hastalar çalışma dışı bırakıldı.

Hastalar bir bilgisayar programı ile Grup TP (Topikal Papaverin) ve Grup USP (Ultrason Papaverin) olmak üzere 2 grup olacak şekilde randomize edildi. Elektrokardiyografi ile kalp atım hızı (KAH) ve ritmi, noninvazif arter kan basıncı (NiKB), invazif arteryel kan basıncı (IKB), periferik oksijen satürasyonu $\left(\mathrm{SpO}_{2}\right)$ ve soluk sonu $\mathrm{CO}_{2}\left(\mathrm{EtCO}_{2}\right)$ monitörizasyonu yapıldı. Anestezi indüksiyonunda tiyopental sodyum 3-5 mg/ $\mathrm{kg}$, remifentanil 0.15-1 $\mathrm{\mu g} / \mathrm{kg} / \mathrm{dk}$. ve rokuronyum 0.6 $\mathrm{mg} / \mathrm{kg}$ uygulanarak entübe edildi. Anestezi idamesi \%5-6 desfluran, remifentanil $0.15-1 \mu \mathrm{g} / \mathrm{kg} / \mathrm{dk}$. ve aralıklı olarak rokuronyum 0.1-0.2 mg/kg ile sağlandı. Hemodinamik stabilizasyon için kristaloid ve kolloid infüzyonların yanı sıra gereği hâlinde inotropik ve vazopresör ajan infüzyonları uygulandı.

Grup USP'ye anestezi indüksiyonu sonrasında cerrahiye başlanmadan Ultrason eşliğinde sol 4. interkostal aralık belirledikten sonra prob sternum kenarına transvers düzleme yerleştirilerek internal interkostal kas, transversus torasik kas ve bu 2 kas arasında seyreden sol internal mammarian arter plevra üzerinde görüldü. Elli mm'lik bir blok iğnesi düzlem içi teknik ile transversus torasik kas ile internal interkostal kas 


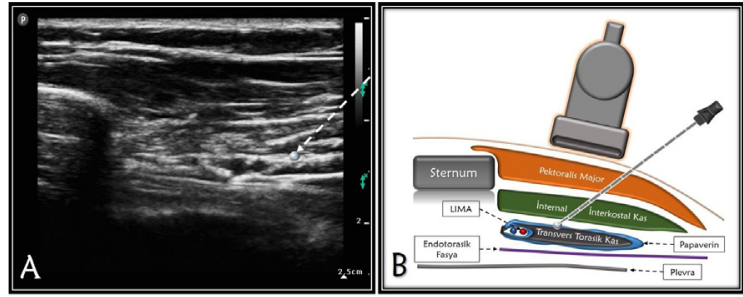

Şekil 1. A) Ultrason eşliğinde transvers torasik kas planına papaverin enjeksiyonu, B) Transvers torasik kas planına papaverin enjeksiyonunun basitleştirilmiş illustrasyonu.

arasındaki plana yerleştirilerek enjeksiyon öncesi 3 $\mathrm{ml}$ serum fizyolojik ile lokalizasyon (planın genişlediği görülerek) doğrulandı. Grup USP $10 \mathrm{mg}$ papaverin $\% 0.9 \mathrm{NaCl}$ ile dilüe edililerek toplam karışım $10 \mathrm{ml}$ olacak şekilde bu plana enjekte edildi (Şekil 1).

Medyan sternotomiden sonra, LIMA düşük güçlü elektrokoter ile distalde bifurkasyondan proksimalde subklavyen vene kadar serbestleştirildi. Ana dallar hemokliplerle bağlandı. LIMA serbestleştirilme zamanı, plevral boşluk açıldıktan sonra başlanarak diseksiyon tamamlanana kadar kaydedildi. Grup TP'de, aynı çözelti, tüm uzunluğu boyunca LIMA pedikülüne, hasattan sonra bir şırıngaya takılan 25 gauge iğne ile püskürtüldü. Her 2 grupta da LIMA papaverin emdirilmiş gazlı beze sarıldı ve torasik kanama kontrol edildi.

Akımlar trans-time akım ölçümü (TTFM) cihazı (MediStim VQ-1101, MediStim ASA, Oslo, Norveç) kullanılarak ölçüldü. Anastomozdan hemen önce LIMA dk. başına serbest akış hesaplandı. Anastomoz sonrasında ise ortalama akım (MFR) ( $\mathrm{mL} / \mathrm{dk}$.), pulsatilite indeksi (PI) ve diyastolik dolum yüzdesi (DF\%) cihaz tarafından otomatik olarak kaydedildi. DF $<\% 50$ ve/veya $\mathrm{Pl}>5$ zayıf akışın bir göstergesi olarak kabul edildi. Ortalama akım, zayıf akışın bir işareti olarak tek başına kullanılmadı ve diğer 2 parametre ile birlikte değerlendirildi. Elde edilen değerlerin yorumlanması, bir greftin revize edilip edilmeyeceğine karar vermemizi olası kıldı. Akış ölçümleri sırasında kardiyopulmoner baypas basınçları $70 \mathrm{~mm}$ Hg'de tutuldu. Ayrıca, pompa süresi, kros klemp süresi ve toplam cerrahi süreler de kaydedildi.
Uygulamaların standardize edilebilmesi için tüm ameliyatlarda uygulamalar aynı anestezi ekibi (MEAAMY) ve aynı cerrahlar (UK) tarafından gerçekleştirilmiştir.

\section{Örneklem Büyüklüğü ve İstatistiksel Analiz}

Bu pilot klinik fizibilite çalışması bir pilot çalışmanın nasıl yapılacağı ile ilgili esaslara ${ }^{[7]}$ uygun olarak dizayn edildiğinden ve önceki benzer çalışmaların olmaması nedeniyle her grup için 20 hastadan oluşan uygun bir örneklem büyüklüğü kullanıldı.

İstatistiksel analiz SPSS yazııım versiyonu 20.0 (IBM Corp., Armonk, New York, ABD) kullanılarak yapıldı. Değişkenlerin dağılımı Kolmogorov-Smirnov ve histogram testleri kullanılarak normallik açısından değerlendirildi. Tanımlayıcı veriler ortalama \pm standart sapma olarak belirtildi. Kategorik değişkenler ki-kare testi kullanılarak analiz edildi. Sürekli değişkenler içeren normal dağıtıımış veri Student t-testi kullanılarak analiz edildi. Normal dağılım göstermeyen verileri analiz etmek için Mann-Whitney $U$ testi kullanıldı. $p<0.05$ istatistiksel olarak anlamlı kabul edildi.

\section{BULGULAR}

Demografik veriler açısından gruplar arasında istatistiksel olarak fark yoktu ( $p>0.05$ ) (Tablo 1). illaç uygu-

Tablo 1. Hastaların demografik özellikleri.

\begin{tabular}{lccc} 
& $\begin{array}{c}\text { Grup USP } \\
(\mathbf{n = 2 0 )}\end{array}$ & $\begin{array}{c}\text { Grup TP } \\
(\mathbf{n = 2 0 )}\end{array}$ & $\mathbf{p}$ \\
\hline Yaş & $59.95 \pm 8.79$ & $57.10 \pm 8.80$ & $0.312^{\mathrm{a}}$ \\
Vücut yüzey alanı $\left(\mathrm{m}^{2}\right)$ & $1.86 \pm 0.16$ & $1.85 \pm 0.17$ & $0.992^{\mathrm{a}}$ \\
EF & $51.25 \pm 6.46$ & $50.50 \pm 6.05$ & $0.599^{\mathrm{b}}$ \\
ASA II/III & $9 / 11$ & $8 / 12$ & $1.000^{\mathrm{c}}$ \\
Diyabetes mellitus & 8 & 6 & $0.741^{\mathrm{c}}$ \\
Hipertansiyon & 9 & 11 & $0.752^{\mathrm{c}}$ \\
Dislipidemi & 6 & 7 & $1.000^{\mathrm{c}}$ \\
Sigara & 9 & 10 & $1.000^{\mathrm{c}}$ \\
& & &
\end{tabular}

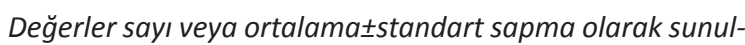
muştur.

USP: Ultrason Papaverin, TP: Topikal Papaverin, EF: Ejeksiyon Fraksiyonu, ASA: Amerikan Anesteziyologlar Derneği

a Student T testi

${ }^{b}$ Mann-Whitney $U$ testi

${ }^{c}$ ki-kare 
M. E. Aydın ve ark., LIMA Serbestleştirilmesi için Papaverinin Transvers Torasik Kas Düzlemi Enjeksiyonu ile Topikal Uygulamasının Karşılaştırılması

Tablo 2. Operatif özellikler.

\begin{tabular}{|c|c|c|c|}
\hline & $\begin{array}{c}\text { Grup USP } \\
(n=20)\end{array}$ & $\begin{array}{c}\text { Grup TP } \\
(n=20)\end{array}$ & $\mathbf{p}$ \\
\hline MAP-T1 (mmHg) & $72.50 \pm 9.46$ & $72.75 \pm 4.35$ & $0.780^{a}$ \\
\hline MAP-T2 (mmHg) & $70.95 \pm 5.19$ & $74 \pm 4.95$ & $0.242^{\mathrm{a}}$ \\
\hline HR-T1 (atım/dk.) & $76.55 \pm 10.20$ & $75.9 \pm 9.73$ & $0.838^{\mathrm{a}}$ \\
\hline HR-T2 (atım/dk.) & $73 \pm 8.72$ & $75.15 \pm 8.32$ & $0.430^{\mathrm{a}}$ \\
\hline $\begin{array}{l}\text { LIMA serbestleme } \\
\text { süresi (dk.) }\end{array}$ & $13.90 \pm 3.01$ & $16.65 \pm 4.50$ & $0.049^{b}$ \\
\hline $\begin{array}{l}\text { Kros klemp süresi } \\
\quad(\mathrm{dk} .)\end{array}$ & $60.10 \pm 15.69$ & $60 \pm 15.35$ & $0.984^{a}$ \\
\hline $\begin{array}{l}\text { Pompa süresi } \\
\text { (dk.) }\end{array}$ & $117.85 \pm 31.53$ & $114.90 \pm 29.17$ & $0.779^{b}$ \\
\hline $\begin{array}{l}\text { Toplam cerrahi süre } \\
\text { (dk.) }\end{array}$ & $217 \pm 35.22$ & $200.05 \pm 29.66$ & $0.095^{b}$ \\
\hline
\end{tabular}

Değerler sayı veya ortalama土standart sapma olarak sunulmuştur.

USP: Ultrason Papaverin, TP: Topikal Papaverin, MAP: Ortalama arteryel kan basıncı, HR: Kalp atım hızı,

T1: Papaverin uygulama zamanı, T2: Ölçüm yapılma zamanı

a Student $T$ testi

${ }^{b}$ Mann-Whitney $U$ testi

Tablo 3. Baypas öncesi ve sonrası LıMA akımları.

\begin{tabular}{lccc} 
& $\begin{array}{c}\text { Grup USP } \\
(\mathbf{n = 2 0})\end{array}$ & $\begin{array}{c}\text { Grup TP } \\
(\mathbf{n = 2 0})\end{array}$ & $\mathbf{p}$ \\
\hline Serbest akım (ml/dk.) & $111.35 \pm 69.76$ & $92.15 \pm 46.76$ & $0.185^{\mathrm{a}}$ \\
MFR (ml/dk.) & $96.15 \pm 47.49$ & $93.85 \pm 37.84$ & $0.914^{\mathrm{a}}$ \\
PI & $1.52 \pm 0.85$ & $1.38 \pm 0.76$ & $0.776^{\mathrm{a}}$ \\
DF \% & $67.30 \pm 6.52$ & $66.80 \pm 7.85$ & $0.828^{\mathrm{b}}$
\end{tabular}

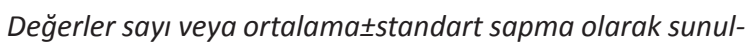
muştur.

USP: Ultrason Papaverin, TP: Topikal Papaverin,

MFR: Ortalama akış hızı, PI: pulsatilite indeksi,

DF: diyastolik dolum

${ }^{a}$ Mann-Whitney $U$ testi

${ }^{b}$ Student T testi

lama ve ölçümler sırasında hemodinamik parametreler karşılaştırıldığında gruplar arasında istatistiksel olarak anlamlı bir farklılık bulunmamaktadır ( $p>0.05$ ).

(Tablo 2).

Kros klemp süresi, pompa süresi ve toplam cerrahi süre her 2 grupta da benzer şekilde seyretse de LIMA serbestleştirilme süresi Grup USP de istatistiksel olarak anlamlı derecede düşük bulunmuştur (13.90 \pm 3.01 vs. $16.65 \pm 4.50$ sırasıyla, $p=0.049$ ).
Akım ölçümleri değerlendirildiğinde anastomoz öncesinde LIMA serbest akımı her ne kadar istatistiksel olarak fark bulunmasa da Grup USP de Grup TP'ye göre yüksek seyretmiştir (111.35 \pm 69.76 vs. $92.15 \pm 46.76$ sırasıyla, $p=0.185)$. Ayrıca anastomoz sonrasında değerlendirilen trans-time akım ölçümleri (MFR, PI, DF) arasında gruplar arasında anlamlı bir fark gözlenmemiştir ( $p>0.05$ ) (Tablo 3).

Grup USP de LIMA serbestleştirme hoşnutluk düzeyi istatistiksel olarak anlamlı düzeyde yüksekti $(p=0.029)$ (Tablo 4).

Tablo 4. Cerrah hoşnutluğu.

\begin{tabular}{lccc} 
& Grup USP (n=20) & Grup TP (n=20) & p \\
\hline Kötü & 0 & 3 & \\
Orta & 3 & 7 & \\
İyi & 8 & 8 & $\mathbf{0 . 0 2 9}$ \\
Çok İyi & 9 & 2 & \\
\hline Toplam & 20 & 20 \\
\hline
\end{tabular}

Değerler sayı olarak sunulmuştur. USP: Ultrason Papaverin, TP: Topikal Papaverin ${ }^{a}$ ki-kare

\section{TARTIŞMA}

Çalışma; CABG cerrahilerinde LIMA serbestleştirilmesi sırasında gelişebilecek spazmın önlenebilmesi için yeni bir yöntem olarak tanımladığımız cerrahi başlamadan önce ultrason eşliğinde papaverinin transvers torasik kas düzlemine enjeksiyonunun etkinliği bilinen ve geleneksel bir yöntem olarak kabul görmüş topikal uygulama ile benzer şekilde etki ettiğini göstermiştir.

Histolojik yapılarının benzerliği ve geometrik uyumu CABG prosedürlerinde LAD grefti için LIMA'yı vazgeçilmez kılan nedenlerdir. LIMA dışında safen ven, radial arter, sağ gastroepiploik arter, inferior epigastrik arter ve lateral femoral arterin inen dalı da LAD grefti olarak kullanılabilmektedir. Ancak, 10 yıllık sağ kalım süreleri incelendiğinde LIMA (\%88-95) en uzun süreye sahipken safen ven (\%32-71) en kısa sürelerle seyretmiştir ${ }^{[8]}$. Bu nedenle LIMA başarılı bir cerrahi 
için optimal şartlarda hazırlanmalı ve korunmalıdır. Tüm bu uyum ve uzun sağ kalım özelliklerine karşın diseksiyonu sırasında gelişen LIMA spazmı greftin kullanılması ve hedeflenen optimum akımların sağlanmasında bilinen en önemli engellerden biridir.

Greftin erken ve geç dönem açıklığını artırmak amacıyla sistemik nitrogliserin-diltiazem, topikal papaverin, topikal milrinon, verapamil-nitrogliserin kombinasyonu gibi farmakolojik yöntemler ve organ banyosu gibi farklı cerrahi tekniklerin yanı sıra anestezistler tarafından gerçekleştirilen stellat ganglion bloğu gibi yaklaşımlar tanımlanmıştır ${ }^{[9]}$. Chandran R. ve ark. anestezi indüksiyonu sonrasında çalışma grubuna sol stellat ganglion bloğu uyguladılar ${ }^{[10]}$. LIMA akımları kontrol grubuna göre yüksek olarak ölçülse de bu fark istatistiksel olarak anlamlı değildi. Her iki gruba da LIMA serbestleştirilmesi sonrasına uygulanan topikal papaverin bu sonucu açıklayabilir. Stellat ganglion bloğunun greft açıklı üzerine etkilerinin çeşitli farmakolojik rejimlerle kıyaslandığı çeşitli çalışmalar literatürde ayrıntılı olarak incelenmiştir ${ }^{[11]}$.

Anatomik komşulukları nedeniyle transversus torasik kas planına preoperatif dönemde ultrason eşliğinde uygulanan papaverin enjeksiyonunun LIMA serbestleştirilmesi sırasında gelişebilecek spazmı ve buna bağlı akımlar üzerinde gelişecek olumsuz etkileri engelleyeceği hipotezi ile tasarladığımız çalışmamızda, yöntemimizi kontrol grubu olarak geleneksel bir yaklaşım olarak kabul görmüş olan topikal papaverin uygulaması ile kıyasladık.

Papaverin, Papaver Somniferum bitkisinden izole edilen ve sentetik olarak üretilen bir alkaloiddir. Direkt etkili bir düz kas gevşetici olan papaverinin etki mekanizması; non-selektif fosfodiesteraz inhibisyonunu ve kalsiyum kanallarının doğrudan inhibisyonudur ${ }^{[12]}$. Erektil disfonksiyon tanı ve tedavisi ${ }^{[13]}$, epilepsi ve status tedavisi ${ }^{[14]}$, migren proflaksisi ${ }^{[15]}$, serebral vazospazm tedavisi ${ }^{[16]}$ gibi farklı endikasyonlarda da kullanım alanları bulmuştur. Günümüzde özellikle endovasküler girişimlerde arteryel vazodilatatör olarak yaygın olarak kullanılmaktadır.
Koroner arter baypas grefti cerrahisinde LIMA spazmının önlenmesi ve tedavisi için geleneksel olarak intralüminal, perivasküler ve topikal papaverin uygulamaları kullanılmaktadır. Intralüminal uygulama sırasında artan gerilim sonucu intima ve internal elastik lamina hasar görebilir ${ }^{[17,18]}$. Serbestleştirilmesi öncesinde LIMA etrafına papaverin enjeksiyonu ile gerçekleştirilen perivasküler enjeksiyon yönteminde enjeksiyon yapılırken, henüz cerrahi diseksiyonun tamamlanmamış olması nedeniyle bölgesel anatomiye egemenlik sağlanamamıştır ve LIMA ponksiyonu riski taşımaktadır ${ }^{[19]}$. Bir başka sorun ise, serbestleştirilmesi öncesinde uygulanan papaverin; yalnızca LIMA ana hattının değil aynı zamanda LIMA yan dallarında da kanlanmayı artırarak kanamaya yol açabilir. Bu pilot çalışmamızda, kanlanma artışına bağlı herhangi bir kanamaya rastlanmadı ama bu risk her zaman göz önünde bulundurulmalı ve buna yönelik cerrahi önlemler alınmalıdır. Bu iki sorun bu yeni tekniğin en önemli dezavantajı olarak sayılabilir. Fakat geniş serili çalışmalar ile bu risklerin ortaya çıkma olasılığı ortaya konabilir. Her ne kadar günümüzde papaverin uygulamasında etkin ve güvenli oluşu nedeniyle topikal uygulama genel kabul gören yöntem olsa da organ banyosu gibi farklı modifikasyonlar ile en etkin yöntem arayışı devam etmektedir ${ }^{\left[{ }^{[9}\right.}$.

Çalışmamızda, ultrason eşliğinde gerçekleştirdiğimiz papaverin enjeksiyonu her ne kadar perivasküler alanı hedeflese de klasik perivasküler enjeksiyon yönteminden önemli noktalarla farklıdır. Gowda GSL ve ark. ${ }^{[19]}$ Çalışmalarında, uyguladıkları perivasküler papaverin enjeksiyonunu ponksiyon riskini minimalize edebilmek için LIMA serbestleştirilmesinden sonra yapmışlardır. Topikal papaverin uygulamasına göre perivasküler enjeksiyon yönteminde daha yüksek LIMA serbest akımları ölçtüler. Ancak tercih ettikleri $0.3 \mathrm{mg} / \mathrm{ml}$ papaverin konsantrasyonu çalışmamızda kullandığımız konsantrasyonla kıyasla oldukça yüksektir ve bu sonuçları etkileyebilir. Çalışmamızda, ultrason eşliğinde gerçekleştirilen papaverin enjeksiyonlarında hedef yapılar daha ayrıntılı bir şekilde görüntülenerek olası LIMA hasarı minimalize edilmiştir. Ayrıca işlem preoperatif dönemde bölge sonoa- 
M. E. Aydın ve ark., LIMA Serbestleştirilmesi için Papaverinin Transvers Torasik Kas Düzlemi Enjeksiyonu ile Topikal Uygulamasının Karşılaştırılması

natomisi konusunda deneyimli anestezistler tarafından gerçekleştirilmiştir.

Greft akımlarını fonksiyonel olarak kolay ve hızlı bir şekilde damar boyutu ve şeklinden etkilenmeden değerlendirilebilmesi TTFM yöntemi ile olasıdır ${ }^{[20]}$. Bir akış probuna sabitlenmiş 2 ultrasonik sensör kullanır. Ultrasonik sinyal 1 sensörden iletilir ve sıvı dolu 1 boruyu geçerek karşılık gelen 2 . 1 sensör tarafından sinyalin alınması ile ölçümler tamamlanır. Ortalama akım greft kalitesine ve çapına, hedef damar kalitesine ve baypasın distal akışına bağlı olacaktır. PI greftteki direnci ve distal-hedef damar akışını tahmin eder. DF, özellikle sol ventrikülün yüksek transmiyokardiyal basınç gradyanlarından dolayı sol koroner sistem için diyastol sırasında sistolik akıştan daha yüksek olması gereken toplam akış yüzdesini hesaplamak için belirlenebilir ${ }^{[21]}$.

Akım ölçümlerinin zamanlaması yayınlanmış çalışmalarda farklılık gösterse de biz en son etkiyi daha doğru değerlendirebilmek için serbestleştirilmesinden hemen sonra değil LIMA-LAD anastomozu safhasından hemen öncesi ve sonrasını baz alarak gerçekleştirdik. Anastomozdan hemen önce gerçekleştirilen LIMA serbest akımları Grup USP de istatistiksel olarak anlamlı olmasa da klinik olarak önemli düzeyde yüksek bulunmuştur.

Tüm bu değişkenlerin ötesinde LIMA diseksiyonunun cerrahi açıdan değerlendirilmesi çalışmanın bir başka anlamlı sonucudur. Ultrason eşliğinde papaverin uygulamasının cilt insizyonundan önce gerçekleştirilmesi endotorasik fasya üzerinde LIMA etrafında papaverinin bir depozit hâlinde daha uzun süre temasını sağlayarak cerrahi diseksiyonu kolaylaştırmıştır.

Bu çalışmanın bazı kısıtlılıkları vardır. Küçük örneklem büyüklüğü, bu çalışmanın ana sınırlamalarından biridir. TTFM ve viskozite birbirlerinden etkilenebilen sürekli değişkenlerdir. Ancak, çalışmamız viskozite ile ilgili herhangi bir veri içermemektedir. Bir diğer kısıtlama ise transvers torasik kas plan enjeksiyonunun deneyim gerektirmesidir. Bu çalışmanın standardizasyonu açısından tüm girişimler aynı anestezistler tarafından gerçekleştirilmiştir. Bu aynı zamanda çalışmanın doğal bir kısıtlayıcısıdır. İlgili bölge anatomisi ve ultrason ile girişim için yeterli tecrübeye sahip olmayan uygulayıcılar LIMA ponksiyonu gibi yıkıcı komplikasyonlar ile karşılaşabilirler. Son olarak, çalışma doğası gereği çift kör bir çalışma olarak tasarlanmamıştır. Gelecekte bu sonuçlarımızı doğrulayacak daha geniş örneklem büyüklüğünde çift kör randomize kontrollü çalışmalara gereksinim vardır.

Çalışmanın sonucunda, sternotomi öncesi LIMA etrafına USG eşliğinde yapılan perivasküler papaverin uygulamasının topikal/perivasküler uygulaması ile benzer şekilde kan akımını artırdığı, LıMA diseksiyon süresini kısalttığı ve cerrahi memnuniyetini artırdığı görülmüştür. Ultrason eşliğinde transvers torasik kas planına uygulanan papaverin enjeksiyonunun LIMA spazmını önlemek için topikal uygulamaya alternatif bir yöntem olabileceğini düşünmekteyiz.

\section{KAYNAKLAR}

1. Mills NL, Bringaze WL, 3rd. Preparation of the internal mammary artery graft. Which is the best method? J Thorac Cardiovasc Surg. 1989;98(1):73-7; discussion 8-9. https://doi.org/10.1016/S0022-5223(19)34463-0

2. Huddleston CB, Stoney WS, Alford WC, Jr., Burrus GR, Glassford DM, Jr., Lea JWt, et al. Internal mammary artery grafts: technical factors influencing patency. Ann Thorac Surg. 1986;42(5):543-9. https://doi.org/10.1016/S0003-4975(10)60579-6

3. Tabel $\mathrm{Y}$, Hepağuşlar $\mathrm{H}$, Erdal $\mathrm{C}$, Catalyürek $\mathrm{H}$, Acikel $\mathrm{U}$, Elar Z, et al. Diltiazem provides higher internal mammary artery flow than nitroglycerin during coronary artery bypass grafting surgery. Eur J Cardiothorac Surg. 2004;25(4):553-9. https://doi.org/10.1016/j.ejcts.2004.01.004

4. Möllhoff T, Schmidt C, Van Aken H, Berendes E, Buerkle $\mathrm{H}$, Marmann $\mathrm{P}$, et al. Myocardial ischaemia in patients with impaired left ventricular function undergoing coronary artery bypass grafting--milrinone versus nifedipin. Eur J Anaesthesiol. 2002;19(11):796-802. https://doi.org/10.1097/00003643-200211000-00004

5. Girard DS, Sutton JP, 3rd, Williams TH, Crumbley AJ, 3rd, Zellner JL, Kratz JM, et al. Papaverine delivery to 
the internal mammary artery pedicle effectively treats spasm. Ann Thorac Surg. 2004;78(4):1295-8. https://doi.org/10.1016/j.athoracsur.2004.01.061

6. Aydin ME, Ahiskalioglu A, Ates I, Tor IH, Borulu F, Erguney OD, et al. Efficacy of Ultrasound-Guided Transversus Thoracic Muscle Plane Block on Postoperative Opioid Consumption After Cardiac Surgery: A Prospective, Randomized, Double-Blind Study. J Cardiothorac Vasc Anesth. 2020;34(11):29963003.

https://doi.org/10.1053/j.jvca.2020.06.044

7. Thabane L, Ma J, Chu R, Cheng J, Ismaila A, Rios LP, et al. A tutorial on pilot studies: the what, why and how. BMC Med Res Methodol. 2010;10:1. https://doi.org/10.1186/1471-2288-10-1

8. Kolh P, Windecker S, Alfonso F, Collet JP, Cremer J, Falk V, et al. 2014 ESC/EACTS Guidelines on myocardial revascularization: the Task Force on Myocardial Revascularization of the European Society of Cardiology (ESC) and the European Association for Cardio-Thoracic Surgery (EACTS). Developed with the special contribution of the European Association of Percutaneous Cardiovascular Interventions (EAPCI). Eur J Cardiothorac Surg. 2014;46(4):517-92.

https://doi.org/10.1093/ejcts/ezu366

9. Ray Mohapatra CK, Mishra P, Saxena P, Raut C, Khandekar J, Ammannaya GK, et al. Use of nitroglycerin and verapamil solution by organ bath technique in preparation of left internal thoracic artery for coronary artery bypass surgery. Indian Heart J. 2017;69(6):772-6. https://doi.org/10.1016/j.ihj.2017.04.004

10. Chandran R, Sreedhar R, Gadhinglajkar S, Dash $P_{\text {, }}$ Karunakaran JPillai V. Combined effect of left stellate ganglion blockade and topical administration of papaverine on left internal thoracic artery blood flow in patients undergoing coronary revascularization. Ann Card Anaesth. 2020;23(2):170-6.

https://doi.org/10.4103/aca.ACA_144_18

11. Demir A, Donmez AErdemli O. Koroner cerrahisinde stellat ganglion blokajı. Anestezi Dergisi. 2011;19(4): 201-7.

12. Hiller KO, Ghorbani M, Schilcher H. Antispasmodic and relaxant activity of chelidonine, protopine, coptisine, and Chelidonium majus extracts on isolated guinea-pig ileum. Planta Med. 1998;64(8):758-60. https://doi.org/10.1055/s-2006-957576

13. Chandeck Montesa K, Chen Jiménez J, Tamayo JC, Rodríguez Antolín A, Alvarez González E. Prospective study of the effectiveness and side effects of intracavernous prostaglandin E1 versus papaverine or papaverine phentolamine in the diagnosis and treatment of erection dysfunction. Review of the literature. Actas Urol Esp. 1992;16(3):208-16.

14. Wirth L. Papaverine hydrochloride in status epilepticus. Mil Med. 1956;118(5):507. https://doi.org/10.1093/milmed/118.5.507

15. Vijayan N. Brief therapeutic report: papaverine prophylaxis of complicated migraine. Headache. 1977;17(4):159-62. https://doi.org/10.1111/j.1526-4610.1977.hed1704159.x

16. Touho H, Furuoka N, Karasawa J. Distribution of intraarterially administered papaverine in endovascular treatment of delayed cerebral vasospasm. Neurol Med Chir (Tokyo). 1997;37(2):163-71; discussion 71-2. https://doi.org/10.2176/nmc.37.163

17. Yavuz S, Celkan A, Göncü T, Türk T, Ozdemir IA. Effect of papaverine applications on blood flow of the internal mammary artery. Ann Thorac Cardiovasc Surg. 2001;7(2):84-8.

18. Van Son JA, Tavilla G, Noyez L. Detrimental sequelae on the wall of the internal mammary artery caused by hydrostatic dilation with diluted papaverine solution. J Thorac Cardiovasc Surg. 1992;104(4):972-6. https://doi.org/10.1016/S0022-5223(19)34680-X

19. Gowda GSL, Kumar JHV, G SV, Mathew AK, Nanjappa MC. Effect of Papaverine on Left Internal Mammary Artery Flow: Topical Spraying versus Perivascular Injection Method. Braz J Cardiovasc Surg. 2020;35(2):181-4. https://doi.org/10.21470/1678-9741-2019-0126

20. Kaya U, ÇolakA, Becit N, Ceviz M, Koçak H. Intraoperative transit-time flow measurement in on-pump coronary artery bypass graft surgery: Single center experience. Turk Gogus Kalp Damar Cerrahisi Derg. 2018;26(2):16776.

https://doi.org/10.5606/tgkdc.dergisi.2018.15004

21. Balacumaraswami L, Taggart DP. Intraoperative imaging techniques to assess coronary artery bypass graft patency. Ann Thorac Surg. 2007;83(6):2251-7. https://doi.org/10.1016/j.athoracsur.2006.12.025 